\title{
Inclusión de aprendizajes en torno a la gestión de riesgo de desastres naturales en instrumentos de planificación territorial (2005 - 2015)
}

\section{Inclusion of learning about management of natural disasters risk in territorial planning instruments (2005 - 2015)}

\author{
Arturo Rinaldi y Kay Bergamini²
}

\begin{abstract}
RESUMEN
Chile se encuentra constantemente asediado por eventos de origen antrópico y natural que, en la mayoría de los casos, devienen en desastres o catástrofes que traen consigo pérdidas humanas y materiales de variada intensidad, cuyo costo se combina con aquel asociado a los sucesivos procesos de reconstrucción que deben ser implementados. Sin embargo no toda amenaza debe, necesariamente, conducir a un desastre; y es allí donde radica el principal aporte de la gestión del riesgo de desastres, que puede ser correctiva, reactiva o prospectiva. El presente artículo busca conocer cómo han influido los desastres naturales ocurridos en Chile en la última década, en la incorporación de la gestión de riesgos de desastre dentro de las normativas urbanas existentes en Chile. Lo anterior partiendo de una hipótesis que plantea que dicha inclusión pareciera ser más bien escasa, y cuando ésta ocurre, tiende a focalizarse principalmente en una gestión del riesgo reactiva.
\end{abstract}

Palabras clave: Desastres, gestión del riesgo, normativa urbana, instrumentos de planificación territorial

\begin{abstract}
Chile is constantly besieged by events of anthropic and natural origin that, in most cases, result in disasters or catastrophes that human and material loses of diverse intensity, whose cost is combined with that associated with successive reconstruction processes that must be implemented. However, the presence of threats in a territory not always lead to the unleashing of a disaster; and this is where the main contribution of disaster risk management lies, which can be corrective, reactive or prospective. This article seeks to know how the natural disasters that have occurred in Chile in the last decade have influenced the incorporation of risk management within the existing urban regulations in Chile. The foregoing is part of a hypothesis that suggests that inclusion seems to be rather scarce, and when it happens, it tends to focus mainly on a reactive disaster risk management.
\end{abstract}

Keywords: Disasters, risk management, urban regulations, territorial planning instruments. 
Debido a sus características geográficas, el territorio chileno configura un complejo escenario desde el punto de vista de los riesgos naturales: se encuentra ubicado en el denominado "Cinturón de Fuego del Pacífico" que atraviesa la cordillera de Los Andes, lo que deriva en una intensa actividad sísmica y volcánica; posee un borde costero de $4.270 \mathrm{~km}$ de longitud, que aumenta su vulnerabilidad ante marejadas y tsunamis; tiene un ancho promedio de $180 \mathrm{~km}$ por lo que en muchas de sus regiones existe un cambio abrupto en el relieve, pasando desde montañas con miles de metros de altura a territorios ubicados a nivel del mar en poca distancia, lo que genera ríos caudalosos e incrementa el riesgo por inundación y remoción en masa (Brain y Mora, 2012). Un ejemplo de lo anterior lo constituye el hecho de que, sólo desde el punto de vista sísmico, Chile haya experimentado 25 terremotos de gran escala en los últimos 130 años y concentre el $7 \%$ de los terremotos superiores a $7^{\circ}$ Richter ocurridos en los últimos 200 años (Tapia, 2003; Moris, 2015). Esto implica que cada 6 años, el país padece de un sismo superior a los 7,5 grados de magnitud, hecho que contrasta contra la recurrencia de 20 años observada en Japón, de 50 años en México y de 90 años en California, Estados Unidos; y lo coloca en el primer lugar a nivel mundial en materia de terremotos (Tapia, 2003).

Sólo entre 2014 y 2015, Chile se vio afectado por 4 eventos naturales que derivaron en importantes impactos negativos para la población e infraestructura de las zonas donde acontecieron: el terremoto y tsunami de Pisagua (01/04/2014), generó daños por 1.200 USD MM\$ y un saldo de 6 fallecidos y más de 900.000 personas evacuadas por la alerta de tsunami; 11 días después ocurrió el incendio de Valparaíso (12/04/2014) que si bien tuvo origen antrópico, también se vio influenciado por condiciones geográficas naturales como pendientes y vientos, dejando un saldo de 15 fallecidos, 10.292 personas afectadas y 2.975 viviendas dañadas; luego de casi un año ocurrió la erupción del volcán Villarrica (03/03/2015) desplazando a más de 5.000 personas; y sólo 22 días después se desarrollaron las inundaciones y aluviones que afectaron a múltiples centros poblados de la Región de Atacama (25/03/2015) dejando un saldo de 31 fallecidos, 86 desaparecidos, 246 personas trasladadas a refugios y la necesidad de invertir más de 500 MM\$ USD en el posterior proceso de reconstrucción; por último, y solo con un mes de diferencia, hizo erupción el volcán Calbuco (25/04/2015) obligando a evacuar más de 6.600 personas y generando una emergencia agrícola y más de 50 MM\$ USD en pérdidas económicas (Cienfuegos, 2015). La realidad que ha sido descrita previamente en términos de existencia de amenazas y ocurrencia de desastres, confirma lo altamente expuesto que se encuentra este país a sufrir los embates de numerosos y frecuentes eventos de origen natural. Es por ello que, desde mediados del siglo XX, Chile ha destinado una importante cantidad de recursos económicos y técnicos a la generación de un marco jurídico e institucional que le permita hacer frente a futuros eventos naturales buscando disminuir sus impactos y la probabilidad de que éstos deriven en desastres.

El panorama de amenazas antes planteado, aunado al hecho de que aproximadamente el $87,8 \%$ de la población chilena habita en áreas urbanas (INE, 2017) provocando aumento en su condición de vulnerabilidad, deriva en la frecuente ocurrencia de catástrofes de origen natural, y por ende, en la constante implementación de procesos de reconstrucción post-catástrofe en diversas comunas del país. "Con el último terremoto, 12 de 15 regiones tienen obras de reconstrucción por catástrofes" expresa un titular de prensa publicado días después de ocurrido el terremoto de Illapel de 2015 (Valencia y Reed, 2015: C10). 
Franchi-Arzola (2015) plantea que la relación entre riesgo ${ }^{3}$ y desastre ${ }^{4}$ no es normal ni esperable, debido a que el último sólo ocurre cuando la gestión del riesgo ha sido inadecuada. De igual forma, coincidiendo con el enfoque de trabajo de esta investigación, el autor mantiene que en Chile existen las condiciones necesarias para poder asumir de forma contundente la planificación y el ordenamiento del territorio; por lo que se requiere iniciar una transición que permita migrar de la cultura de la emergencia y la resistencia que por años ha predominado en el país, hacia una estrategia que se centre en la planificación, resiliencia y adaptación mediante la inclusión del riesgo dentro del marco legal urbanístico a nivel nacional (Franchi-Arzola, 2015).

La motivación para la realización de éste artículo nace de la extensiva revisión y posterior análisis de una problemática que, si bien genera un intenso debate en los días sucesivos a la ocurrencia de un desastre natural en el país, a los pocos meses su impacto es bajo desde el punto de vista de inclusión de la gestión del riesgo en las normativas urbanas que rigen ante la ocurrencia de un evento. Ya lo decía el Subsecretario del Interior, Mahmud Aleuy, en declaraciones realizadas los días posteriores a la ocurrencia de aluviones en el Norte de Chile en 2015: "hay un problema que nadie quiere asumir hasta ahora, y es que los municipios, y en particular sus autoridades, los alcaldes, deben impedir que los planes reguladores permitan que las casas se construyan en zonas aluvionales, que están todas definidas (...)" (Bustos, Herrera y Labrín, 2015). Tan sólo unos meses después, el Subsecretario volvería a insistir en la urgencia de debatir en torno a la necesidad de cambiar los planes reguladores para evitar situaciones de riesgo como las observadas en Coquimbo, luego de ocurrido el terremoto de Illapel que afectó a Coquimbo con un tsunami: "hay que hacer una discusión definitiva como país, para no seguir construyendo bajo la cota de 20 metros (...)" (El Mostrador, 2015).

En vista del escenario antes descrito, el presente artículo tiene como foco el estudio y análisis de las normativas urbanas de alcance nacional e instrumentos de planificación territorial (IPT) de un conjunto de comunas afectadas por desastres naturales, con la finalidad de determinar cuál ha sido el aprendizaje que se ha generado en el Estado producto de la ocurrencia de dichos eventos catastróficos, y cómo este ha sido incorporado dentro de las diferentes regulaciones existentes. Esto, partiendo de la hipótesis de que dicha incorporación es todavía escasa en el momento previo y posterior a la ocurrencia de un evento de origen natural en Chile; y en aquellos casos en que esta es incluida tiende a ser de tipo reactiva (preparación y respuesta a emergencias) más que prospectiva (evitar generación de riesgo futuro) o correctiva (reducir riesgos existentes).

En función de ello la presente investigación se estructuró metodológicamente como un estudio de tipo exploratorio y descriptivo desarrollado bajo un enfoque mixto: exploratorio debido a que el tema de interés ha sido poco indagado; descriptivo, debido a que para efectuar el análisis del marco legal urbanístico nacional y comunal, fue necesario realizar primero una exposición detallada de cada uno de los elementos que lo componen; y con enfoque mixto, debido a que la investigación mezcló la cuantificación de las normas, regulaciones e IPT promulgados durante la década en estudio; con la interpretación de los resultados obtenidos del

Grado de probabilidad de que se produzca una interrupción seria en el funcionamiento de una comunidad o sociedad que resulte en consecuencias perjudiciales (pérdidas humanas, económicas y ambientales) producto de la exposición de personas y bienes vulnerables frente a una amenaza, durante un período de tiempo determinado (Chuquisengo, 2011, pág. 11).

El riesgo es una función de la amenaza por la vulnerabilidad y que por ende "todos los eventos mencionados, cuando interactúan con asentamientos humanos vulnerables, pueden desencadenar un desastre" (Arenas et al, 2010,pág. 2) 
análisis ejecutado, lo que otorga un carácter cualitativo a la investigación. El diseño se considera del tipo no experimental "longitudinal panel" por implicar el estudio del objeto de interés en su contexto natural mediante la recolección de información relativa a un conjunto definido de normas, regulaciones e IPT asociados a los casos de estudio que fueron definidos (Hernández, Fernández y Baptista, 2010).

Respecto al marco temporal dentro del que se sitúa la presente investigación, es necesario aclarar que fue definido considerando que el año 2010 constituye un hito que marcó un antes y un después en la forma en que el Estado chileno aborda los procesos de gestión de riesgo de desastre (Latin Lab, GSAPP Columbia University y Santiago Research Cell, 2015; Moris, 2014; Naciones Unidas, 2010), con lo cual la elección de la década 2005-2015 permitió a los investigadores poner en contraste las actuaciones del Estado previo y posterior a la ocurrencia del terremoto y tsunami del $27 \mathrm{~F}$ de 2010. Lo anterior es relevante pues permite comprobar la capacidad de reacción de un periodo reciente del Estado chileno en incorporar y adaptar las normativas e instrumentos dispuestos para el ordenamiento territorial en Chile, verificando el aprendizaje o no de tales experiencias.

Por último, la presente investigación abarca dos unidades de análisis o muestras: las normativas de alcance nacional y los IPT correspondientes al ámbito comunal. Sin embargo, para la definición del universo dentro del que se enmarca dicho análisis, fue necesario llevar a cabo procesos de selección que permitieran acotar los elementos que componen la muestra. En función de ello, la muestra a emplear en esta investigación es de tipo no probabilística o dirigida debido a que para la determinación de sus elementos se recurrió a un conjunto de condicionantes establecidas por los investigadores como criterios de selección; esto con el objetivo de reducir tanto el número de normas y actos como el número de comunas que podías ser consideradas como casos de estudio, descartando aquellos que no cumplieran con los requisitos definidos (Hernández, Fernández y Baptista, 2010).

Una vez definidos los elementos que componen cada una de las muestras antes mencionadas, se procedió a la recolección de información sobre éstas. Para ello se eligió como técnica de recolección la aplicación de un cuestionario a cada muestra, compuesto por múltiples criterios de clasificación y evaluación ordenados en una tabla, lo que permite un fácil llenado y garantiza una excelente sistematización de la información, con miras a poder producir cruces de datos y generar insumos para su análisis. Dichos cuestionarios se componen por una sección inicial en donde se recopilan datos básicos de cada documento analizado, y una segunda sección orientada a identificar cual es el abordaje que realiza cada documento respecto de la GRD. Interesa puntualizar que dentro de los campos que componen la segunda sección, existe uno que contiene los criterios de evaluación de mayor relevancia a efectos del análisis a realizar posteriormente.

Ya recopilada la información, se procedió a la construcción de una línea de tiempo, entre los años 2005 y 2015, como técnica de análisis que permite evidenciar los vínculos existentes entre las promulgaciones y modificaciones realizadas y los desastres ocurridos en los tres casos de estudio, para así poder evaluar la inclusión de la GRD dentro del marco legal y normativo revisado. A partir de esta línea de tiempo fue posible generar diversos cruces de información, cuyos detalles y resultados se presentarán más adelante. 


\section{Componentes del riesgo y mecanismos para su gestión}

Si bien es posible asumir que los términos amenaza, vulnerabilidad y riesgo son ya ampliamente conocidos y cuentan con numerosas definiciones, a continuación se realiza una breve pero necesaria revisión de los mismos con el fin de poder comprender el marco en el que se ubica la presente investigación.

En el contexto anterior una amenaza se define como "un evento físico potencialmente perjudicial, fenómeno natural y/o actividad humana que puede causar la muerte o lesiones, daños materiales, interrupción de la actividad social y económica o degradación ambiental" (EIRD-ONU, 2004: 2). Como complemento Arenas, Lagos e Hidalgo (2010) conciben las amenazas como un factor externo de riesgo, representado por la potencial ocurrencia de un suceso de origen natural que puede manifestarse en un lugar específico, con una intensidad y duración determinadas. El origen de las amenazas puede ser de índole natural o antrópico; sin embargo, a los efectos del presente estudio, el énfasis estará colocado únicamente en el primer tipo de éstas. En ese sentido se tiene que existen tres tipos de amenazas naturales, las cuales pueden ser encontradas a lo largo del territorio chileno y consisten en amenazas geológicas, hidrometeorológicas y biológicas. Las amenazas geológicas involucran procesos terrestres internos como terremotos, actividades y erupciones volcánicas, y procesos geofísicos como movimientos de masa, derrumbes, tsunamis; aquellas consideradas como hidrometeorológicas responden a procesos de origen atmosférico, hidrológico u oceanográfico y comprenden sequías, temporales, huracanes, marejadas, inundaciones, aluviones, nevadas, olas de calor o frío; por último se tiene a las amenazas biológicas, las cuales son fenómenos de origen orgánico o transportados por vectores biológicos, entre las que vale mencionar al hantavirus y las mareas rojas por ser las de mayor impacto en el territorio chileno (Arenas et al, 2010: 2; EIRD-ONU, 2004: 2; EIRD-ONU, 2009: 5).

Sin embargo, la existencia de los distintos tipos de amenazas antes mencionados no conduce necesariamente a un desastre, ya que para que esto último ocurra se requiere que exista un asentamiento humano vulnerable que se vea afectado por éstas. La vulnerabilidad corresponde a un factor interno del riesgo que mide el grado de susceptibilidad y exposición al impacto negativo de amenazas que presenta una comunidad, recurso natural o propiedad producto de la interacción de factores o procesos físicos, sociales, económicos y ambientales (EIRD-ONU, 2004: 7; Randolph, 2004: 201). Cabe acotar que la susceptibilidad refiere al nivel de resistencia y protección frente al impacto de una amenaza que presenta una comunidad, mientras que la exposición se relaciona con decisiones y prácticas que ubican a una unidad social dentro del área de influencia de un fenómeno natural peligroso (Chuquisengo, 2011: 11).

Revisados los conceptos de amenaza y vulnerabilidad, es posible entender al riesgo como el grado de probabilidad de que se produzca una interrupción seria en el funcionamiento de una comunidad o sociedad que resulte en consecuencias perjudiciales (pérdidas humanas, económicas y ambientales) producto de la exposición de personas y bienes vulnerables frente a una amenaza, durante un período de tiempo determinado (Chuquisengo, 2011: 11). En ese sentido es relevante el énfasis que colocan Thomalla et al. (2018) en la relación intrínseca existente entre desarrollo y riesgo de desastre, planteando que mientras no se genere una transformación del paradigma de desarrollo actual, hacia uno centrado en la sostenibilidad y reducción de los distintos factores de vulnerabilidad (inequidad, injusticia, bajos ingresos), las pérdidas económicas y no económicas 
generadas por la ocurrencia de desastres continuarán incrementando, impactando con mayor profundidad las naciones con menos recursos y por ende, más vulnerables.

De lo anterior se puede extraer que la probabilidad de que se genere un desastre ante la manifestación de una amenaza dependerá del grado de vulnerabilidad que presenten la población o los bienes expuestos (Figura No 1). Esta opinión es compartida tanto por Arenas et al (2010), al afirmar que el riesgo es una función de la amenaza por la vulnerabilidad y que por ende "todos los eventos mencionados, cuando interactúan con asentamientos humanos vulnerables, pueden desencadenar un desastre" (pág. 2); como por Lagos, Cisterna y Mardones (2008) al plantear que "la escasa consideración de la dinámica y recurrencia de procesos naturales extremos y su relación con el emplazamiento de viviendas puede tener consecuencias no deseadas, induciendo el riesgo de desastre" (pág. 6).

Figura $\mathrm{N}^{\circ} 1$

Componentes del Riesgo

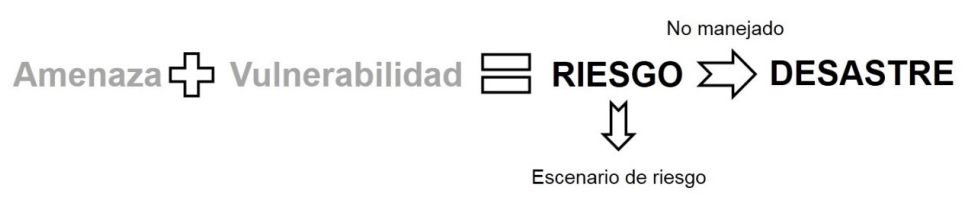

Fuente: Elaboración propia en base a Chuquisengo (2011)

Ante este escenario, y en vista de que gran parte del territorio chileno está expuesto a amenazas de desastres naturales, el manejo del riesgo constituye un elemento clave en la toma de decisiones de planificación urbana. En este sentido, uno de los objetivos de la Política Nacional de Desarrollo Urbano (PNDU), en el marco del ámbito temático asociado con el equilibrio ambiental, se enfoca en identificar y considerar los riesgos naturales y antrópicos colocando el énfasis en incorporar dentro de los IPT: conocimientos sobre los distintos tipos de riesgos; el concepto de reducción del riesgo de desastres, planes de monitoreo y gestión de emergencias; y normas para emplazar construcciones en áreas de riesgo de forma segura; todo lo anterior con la finalidad de disminuir la vulnerabilidad existente en los asentamientos humanos (MINVU, 2014: 43). Con este fin se requiere llevar a cabo un análisis y gestión adecuada del riesgo que permitan diagnosticarlo para luego implementar medidas y mecanismos de prevención y mitigación orientados a disminuir su impacto.

\section{Enfoques de la Gestión del Riesgo de Desastres}

La Gestión de Riesgo de Desastres (GRD) es definida por Chuquisengo (2011) y EIRD-ONU (2009) como un proceso sistemático centrado en la utilización de un conjunto de decisiones administrativas, organizativas y de conocimientos operacionales con el fin de ejecutar políticas y estrategias orientadas tanto a la reducción del impacto adverso de las amenazas naturales y antrópicas, como de aquellas condiciones de riesgo que pudiesen derivar en la ocurrencia de un desastre en una comunidad, región o país. La GRD es un proceso planificado, concertado, participativo e integral, y se encuentra compuesta por tres enfoques o vertientes principales presentadas a continuación (Chuquisengo, 2011): 
Cuadro 1

Enfoques de Gestión de Riesgo de Desastres

\begin{tabular}{|l|l|l|}
\hline \multicolumn{1}{|c|}{ Correctiva } & \multicolumn{1}{|c|}{ Prospectiva } & \multicolumn{1}{c|}{ Reactiva } \\
\hline $\begin{array}{l}\text { Busca reducir los riesgos ya } \\
\text { existentes. }\end{array}$ & $\begin{array}{l}\text { Busca evitar la generación de } \\
\text { riesgos aún no existentes }\end{array}$ & $\begin{array}{l}\text { Busca la preparación y res- } \\
\text { puesta a emergencias. }\end{array}$ \\
\hline
\end{tabular}

Fuente: Elaboración propia según Chuquisengo, 2011.

Como se expresa en el Cuadro 1, la gestión correctiva refiere al conjunto de acciones orientadas a reducir riesgos existentes producto de prácticas inadecuadas e irresponsables de un uso o emplazamiento de la población en el territorio. Estas intervenciones pueden ser superficiales, cuando se busca incidir en la condición de inseguridad mediante una obra de mitigación; o radicales, cuando las acciones se enfocan en incidir sobre las dinámicas causantes de las condición de inseguridad mediante la modificación de patrones de acceso y uso de recursos, o de la injerencia en los procesos de toma de decisiones y del manejo de información relevante respecto del riesgo de desastre (Narváez, Lavell y Pérez, 2009).

La gestión prospectiva, por su parte, refiere a todas aquellas prácticas que se orientan a garantizar que el riesgo y sus factores no se consoliden en el territorio al evitar procesos y decisiones que puedan desencadenar futuras condiciones de riesgo, y que generen la necesidad de aplicar medidas de gestión correctivas. Esta variante de la gestión del riesgo centra su acción en el ordenamiento territorial, y las normativas de construcción e inversión pública y privada, con el fin de garantizar que éstas incluyan y consideren el análisis del riesgo existente (Narváez, Lavell y Pérez, 2009).

La tercera variante de la GRD corresponde a la gestión reactiva, proceso mediante el cual la sociedad y sus instituciones se preparan para enfrentar de forma oportuna y adecuada los efectos de un desastre o emergencia. Estas medidas hacen frente a las consecuencias originadas por la ocurrencia del evento y se enfocan en proteger la vida humana, reducir las pérdidas, atender a los afectados y restablecer las condiciones originales de la zona afectada evitando reconstruir las condiciones de riesgo que condujeron al desastre (UNICEF et al, 2010: 94). Dentro de este tipo de gestión de riesgo es posible situar los procesos transformativos que se originan o pueden incentivarse posterior a la ocurrencia de un desastre, y que llevan tanto a procesos innovadores e inclusivos de toma de decisiones, como a la creación de grupos y redes fuera del ámbito tradicional de organización comunitaria manejado por las instituciones del Estado; generando un camino alternativo hacia la reducción sostenida del riesgo y el desarrollo sostenible (Thomalla et al. 2018).

Una postura alternativa a la comprensión de la GRD como una composición de tres variantes, es aquella postulada por Beatley (2009), quien plantea que la planificación para las amenazas naturales se encuentra conformada por 4 etapas: Prevención/Mitigación, Preparación, Respuesta y Recuperación; las que agrupadas conforman el Marco PPRR para la gestión de desastres. Respecto a éstas 4 etapas el autor aclara que la prevención y mitigación se enfocan en medidas de largo plazo que buscan reducir el riesgo existente (asimilable a una gestión correctiva); la preparación abarca las acciones a tomar previo a la ocurrencia de un desastre natural con el fin de prever, res- 
ponder y recuperarse de forma efectiva de sus impactos probables evitando la generación de un nuevo riesgo (asimilable a una gestión prospectiva); y la respuesta y recuperación se orientan hacia aquellas actividades desarrolladas inmediatamente después de la ocurrencia del evento, con el fin de reducir sus impactos y atender las necesidades generadas a partir de este (asimilables a una gestión reactiva) (Beatley, 2009; UNESCO, 2012).

\section{Resiliencia, adaptación y aprendizaje post-desastre}

El incipiente rol que han desempeñado los IPT existentes respecto de la gestión del riesgo, ha traído como consecuencia la entrada de Chile en un círculo vicioso descrito por Randolph (2004) como el síndrome Desastre-Recuperación-Reconstrucción-Desastre. Este consiste en que luego de ocurrido un desastre, el gobierno se enfoca automáticamente en proveer los recursos económicos y humanitarios necesarios para iniciar la recuperación post-desastre (en Chile esto ocurre durante la fase de emergencia); culminados los tres meses correspondientes a dicha fase, se da paso al proceso de reconstrucción (que por lo general dura 6 meses), el cual considera tanto la construcción de obras de infraestructura como la implementación de los proyectos asociados a los planes estratégicos que se hayan generado pero, por lo general, adolece de un correcto abordaje de los planes reguladores existentes en las comunas afectadas. Esto último refiere a que es común que durante la fase de reconstrucción se soslaye el correcto abordaje de las amenazas y vulnerabilidades existentes en el sitio afectado, derivando en la prevalencia del riesgo por desastre y generándose una alta probabilidad de ocurrencia de una nueva catástrofe cuando los factores de riesgo omitidos vuelvan a entrar en interacción (Figura 2).

Figura 2

Síndrome DRRD

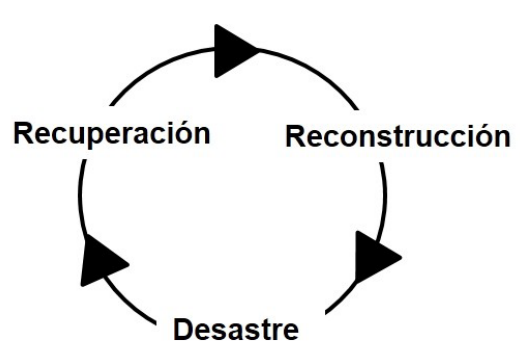

Fuente: Elaboración propia en base a Randolph (2004)

En vista de la problemática descrita, se parte de la premisa de que para comenzar a superar el círculo vicioso antes mencionado es necesaria la implementación de una gestión de riesgo de desastres que tienda hacia un enfoque prospectivo y correctivo, más que hacia uno reactivo. Lo anterior será posible en la medida en que, como plantea el ex - jefe de la División de Desarrollo Urbano del MINVU Pablo Contrucci en sus presentaciones, se realicen modificaciones a la normativa urbana vigente de forma posterior a la ocurrencia de un desastre para así prevenir y prepararse adecuadamente ante futuros eventos, disminuyendo el impacto multidimensional asociado a los desastres (Figura 3). 
Figura 3

Alternativa al Síndrome DRRD

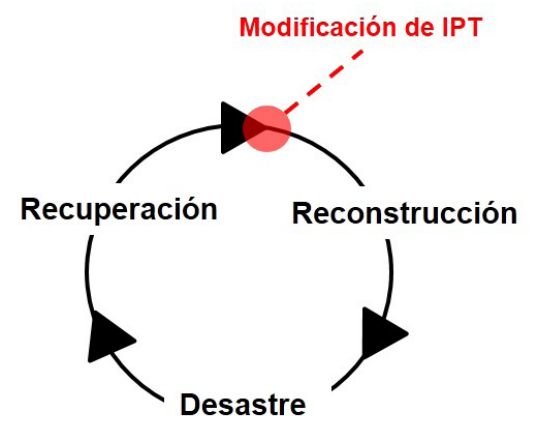

Fuente: Elaboración propia en base a Contrucci (2015)

Sin embargo, para poder romper con dicho círculo vicioso es necesario que el marco jurídico existente en torno a la GRD en Chile se familiarice, reconozca e integre cada vez más conceptos como resiliencia y adaptación. La resiliencia consiste en la capacidad que tiene una persona o grupo, para recuperarse frente a la incertidumbre y hacer frente a nuevo evento con estrategias y tácticas que consideren la memoria histórica y las características preexistentes del tejido socio-territorial afectado (Contreras y Beltrán, 2015). Por ello, las autoras no definen este concepto como una característica, plan o medida a seguir, sino como una condición que posee determinado territorio para sobreponerse ante efectos adversos e inesperados; condición que tendrá mayor presencia y relevancia en aquellos contextos en donde exista un fuerte compromiso del Estado con la planificación territorial, y una adecuada articulación con promotores privados y con la comunidad. El desarrollo resiliente al clima en los contextos urbanos se encuentra orientado tanto a la forma en la que los individuos, comunidades y sistemas manejan y responden a los impactos y presiones climáticas; como a la búsqueda de oportunidades para transformar los procesos de desarrollo urbano y enfocarlos bajo una perspectiva holística respecto al sistema urbano que considere la naturaleza compleja e interconectada del ordenamiento urbano de la ciudad, sus activos físicos, funciones y dimensiones socioeconómicas (Hábitat III, 2015). Es importante mencionar que los factores que influyen en la resiliencia de una ciudad incluyen la intensidad y extensión de los peligros o amenazas; el riesgo presente en torno a las vidas y la propiedad; la vulnerabilidad y exposición de los distintos sistemas que se relacionan en el contexto urbano; y el grado de preparación existente en los sistemas físicos y de gobernanza, frente a cualquier choque o presión (Hábitat III, 2015). Como contrapunto del planteamiento previo, destaca la visión propuesta por Thomalla et al. (2018) respecto a la necesidad de impulsar procesos de transformación en el desarrollo de un territorio o sector poblado, con la finalidad de romper con un status quo institucional y social que puede constituir en sí mismo un factor de vulnerabilidad que evite la adecuada gestión del riesgo de desastre presente.

Respecto a la adaptación, y basado en autores que trabajan en relación al cambio climático, Bajracharya, Childs y Hastings (2011) plantean que las medidas tomadas en este sentido implican aumentar la capacidad que tiene la población para hacer frente a cambios y construir resiliencia comunitaria basándose en el análisis del riesgo, evaluación y vulnerabilidad. Cote (2011) por su 
parte establece que un plan de adaptación refiere a cualquier planificación y política de uso del suelo desarrollada por una agencia regional o municipal, enfocada en dar respuesta a los impactos físicos que se pueden producir. En concreto la planificación adaptativa a nivel municipal implica adquirir y regular el suelo, incorporando nuevas técnicas de gestión institucional e interpretando la información científica existente para luego traducirla en estrategias de planificación del uso del suelo que permitan reducir el riesgo actual y futuro (asociado al cambio climático) que afecta a una comunidad; fomentando la prevención y preparación, y facilitando la respuesta y recuperación por parte de dicha comunidad (Bajracharya et al., 2011; Cote, 2011). Sin embargo, Camacho (2014), señala que la adaptación efectiva de la gestión de recursos naturales en torno a los efectos del cambio climático depende del desarrollo de una infraestructura regulatoria que ofrezca a los actores públicos y privados, la capacidad de evaluar y gestionar la incertidumbre. Esta, por su parte, permite resaltar el valor que tienen la experimentación y el aprendizaje regulatorio dentro de un sistema de gobierno compuesto por diferentes niveles y jerarquías, sugiriendo un papel crucial para los gobiernos nacionales y las instituciones internacionales, de promover el aprendizaje institucional y el intercambio de información inter-jurisdiccional.

En línea con lo anterior, es relevante mencionar el rol que desempeña la gestión ambiental adaptativa respecto del manejo de la incertidumbre, lo inesperado y lo desconocido; ya que plantea la implementación de una estrategia que acepta que todo sistema ambiental contiene sorpresas o hechos inesperados que pueden llevar a una política o acción cuidadosamente definida y funcional, a convertirse en inapropiada de un momento a otro (Mitchell, 1999). Debido a lo anterior, surge la necesidad de realizar cambios o ajustes a dichas políticas, para lo cual Holling (1978) recurre al enfoque de prueba y error como mecanismo que, fijando su punto de partida en aquello que se conoce, permite aumentar la información sobre los factores desconocidos a partir de los aprendizajes obtenidos de los fallos o errores generados producto del proceso de experimentación (Mitchell, 1999).

Como consecuencia es interesante notar, que tal como lo indica Villagra et. al. (20l6): "el pensamiento resiliente sugiere que la resiliencia se debe abordar como un proceso, no como un resultado, lo cual podría ser lo más difícil de lograr", e incluye lo que plantea Aldunce et. al. (2014) como resultado de sus trabajos respecto de que "es importante usar el tiempo entre desastres como "tiempos de paz" para reflexionar y negociar esas plataformas importantes para la preparación". Por lo tanto, existe una estrecha relación entre resiliencia y adaptación, ya que ambas involucran la incorporación de nuevos aprendizajes producto de la experiencia, pero esto "siempre que las estrategias estén orientadas a recuperar la funcionalidad y el equilibrio, al mismo tiempo que se intenta adaptar el contexto local a la nueva configuración urbana" producto del desastre natural tal como menciona Bozza et. al. (2015).

\section{Marco jurídico nacional y comunal regulatorio del desarrollo urbano}

El ámbito jurídico en el cual coloca foco la presente investigación se encuentra fundamentado en la pirámide jurídica urbanística (Cordero, 2007), la cual se encuentra coronada por la Constitución Política de Chile, a la que le siguen por jerarquía las leyes (2do nivel), reglamentos (3er nivel), y los instrumentos de planificación territorial (4to nivel) como se observa a continuación (Figura $N^{\circ} 4$ ). 
Figura 4

Pirámide Jurídica Urbanística

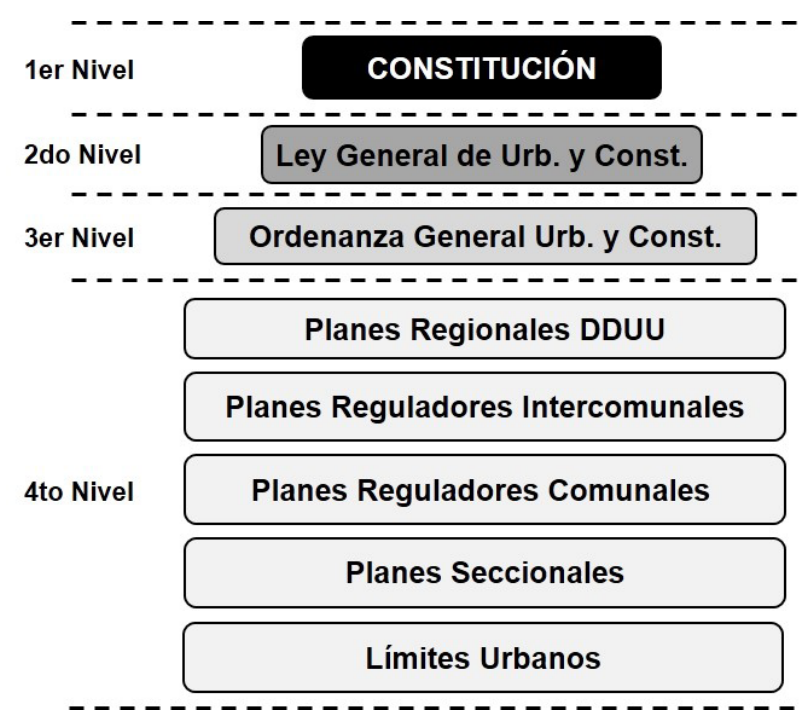

Fuente: Elaboración propia en base a Santa María (2015)

Dicha jerarquía corresponde con lo expresado en el artículo 2.1.1 de la OGUC (1992), en donde se establece que las normas de la Ley General de Urbanismo y Construcciones y su correspondiente Ordenanza, prevalecen sobre las disposiciones contenidas en los IPT respecto a las mismas materias. Con relación a estos últimos, el artículo en cuestión establece que su principal finalidad es facilitar el proceso de planificación urbana destinado a orientar y regular el desarrollo de los centros urbanos. Para ello, cada IPT posee un ámbito de acción particular, asociado tanto a superficie territorial como a materias y disposiciones contenidas, constituyéndose un sistema en el que las disposiciones del IPT de mayor nivel priman y mandatan la acción del instrumento que le sigue en jerarquía.

\section{Marco legal urbano de alcance nacional y gestión del riesgo}

Tomando como base la pirámide jurídica representada en la figura previa, se tiene que a la misma fue necesario incorporarle ciertas modificaciones que permitieran abarcar adecuadamente el objeto de estudio, el cual no sólo corresponde al ámbito de lo urbano sino que también considera la temática relacionada con la GRD. En consecuencia, se consideró relevante incluir la Ley 18.415 de los Estados de Excepción (15/02/1991), Ley 20.582 de Reconstrucción ${ }^{5}$ (04/05/2012) y Ley 16.282 de Sismos y Catástrofes (25/06/1977) en el segundo nivel jerárquico; y tres tipos de

Se aclara que la Ley 20.583 de Reconstrucción, no constituye una ley en sí misma sino que corresponde a una modificación de las normas legales de urbanismo y construcciones para favorecer la reconstrucción; razón por la cual se conoce con el nombre en cuestión. 
actos administrativos (Circulares DDU MINVU, Boletines de Jurisprudencia de Contraloría y Dictámenes Generales y Municipales de Contraloría) en un nivel que abarca de manera transversal los elementos que pertenecen al 3er y 4to nivel de jerarquía, lo que resultó en una nueva pirámide jurídica urbanística (Figura 5).

Figura 5

Pirámide Jurídica Urbanística modificada

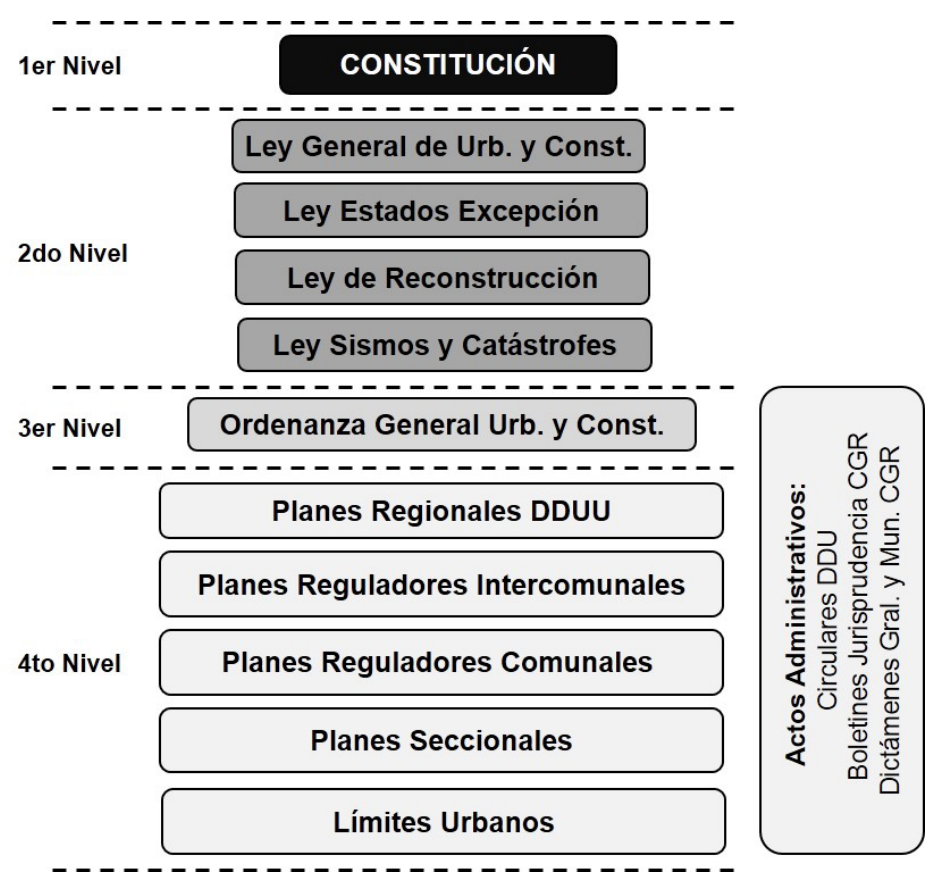

Fuente: Elaboración propia en base a Santa María (2015)

Una vez definidos los documentos legales a analizar, fue necesario reducir el número de documentos a pesquisar aplicando criterios diferenciados por jerarquía dentro de la pirámide jurídica, sobre los cuales se ahonda a continuación.

En el caso de las seis normas de alcance nacional que conforman el $1^{\text {er }}, 2^{\text {do }}$ y $3^{\text {er }}$ nivel de la pirámide, se realizó una revisión detallada de las modificaciones que ha recibido cada una y que se encuentran consignadas en el portal Ley Chile, identificando en total 22 modificaciones de interés para el análisis.

En el caso de los IPT pertenecientes al $4^{\text {to }}$ nivel jerárquico de la pirámide, la revisión fue realizada haciendo uso del Archivo Nacional de IPT perteneciente al Observatorio Urbano del MINVU, con la finalidad de identificar qué IPTs se encuentran vigentes en las comunas elegidas como casos de estudio, y cuáles han recibido modificaciones entre los años 2005 y 2015. Importa señalar que en secciones posteriores del presente artículo se ahonda en el proceso de selección de los casos de estudio empleados para esta investigación. 
Finalmente, en el caso de los actos administrativos se hizo uso de las bases de datos presentes en los portales del MINVU y la Contraloría General de la República, siendo necesario aplicar como primer filtro la década en estudio (2005-2015), luego un segundo filtro mediante palabras clave; y un tercer filtro en donde se revisó en detalle los documentos resultantes para descartar aquellos sin interés para la investigación. Este proceso de filtrado permitió reducir drásticamente el número de documentos, que en conjunto sumaban aproximadamente 50.000 elementos, a tan solo 50 elementos entre los 4 tipos de actos administrativos ya mencionados.

\section{Normas nacionales y abordaje del riesgo}

Una vez realizado el análisis de los documentos previamente listados se tiene que, en el caso de las seis normas analizadas entre 2005 y 2015, se observó que sólo 2 hacen referencia al riesgo; 4 de ellas no involucran ningún tipo de riesgo; todas abordan desastres naturales pero sólo 2 abordan desastres de ambos orígenes; sólo 2 fueron emitidas luego de la ocurrencia de un desastre natural (Ley de Reconstrucción y Ley de Sismos y Catástrofes), y de igual forma 2 hacen referencia al riesgo y al establecimiento de zonas de protección o uso restringido por presencia de amenazas naturales o antrópicas (LGUC, OGUC) (Cuadro 2).

Cuadro 2

Abordaje del riesgo en normas nacionales

\begin{tabular}{|l|c|c|c|c|c|}
\hline Tipo de Acto & $\begin{array}{c}\text { Menciona } \\
\text { Riesgos }\end{array}$ & $\begin{array}{c}\text { Tipos de } \\
\text { Riesgo }\end{array}$ & $\begin{array}{c}\text { Tipo de } \\
\text { Desastre }\end{array}$ & $\begin{array}{c}\text { Emitida } \\
\text { posterior } \\
\text { a un } \\
\text { desastre }\end{array}$ & $\begin{array}{c}\text { Refiere a zonas } \\
\text { de protección o } \\
\text { uso restringido }\end{array}$ \\
\hline $\begin{array}{l}\text { Constitución Política de } \\
\text { la República de Chile }\end{array}$ & NO & Ninguno & Ambos & NO & N/A \\
\hline $\begin{array}{l}\text { Ley de los Estados de } \\
\text { Excepción }\end{array}$ & NO & Ninguno & Ambos & NO & N/A \\
\hline Ley de Reconstrucción & NO & Todos & Natural & SI & NO \\
\hline $\begin{array}{l}\text { Ley de Sismos y } \\
\text { Catástrofes }\end{array}$ & NO & Todos & Natural & SI & NO \\
\hline $\begin{array}{l}\text { Ley General de } \\
\begin{array}{l}\text { Urbanismo y } \\
\text { Construcciones }\end{array}\end{array}$ & SI & Todos & Natural & NO & SI \\
\hline $\begin{array}{l}\text { Ordenanza General } \\
\text { de Urbanismo y } \\
\text { Construcciones }\end{array}$ & SI & Todos & Natural & NO & SI \\
\hline \begin{tabular}{l} 
Total \\
\hline
\end{tabular} & $\begin{array}{c}\text { SI (2) } \\
\text { NO (4) }\end{array}$ & $\begin{array}{c}\text { Todos (4) } \\
\text { Ninguno (2) }\end{array}$ & $\begin{array}{l}\text { Ambos (2) } \\
\text { Natural (4) }\end{array}$ & $\begin{array}{c}\text { SI (2) } \\
\text { NO (4) }\end{array}$ & $\begin{array}{r}\text { SI (2), NO (2), } \\
\text { N/A (2) }\end{array}$ \\
\hline
\end{tabular}

Fuente: Elaboración propia (2016) 
De forma complementaria, y producto de la revisión normativa realizada, fue posible identificar el tipo de GRD que abordan los 6 cuerpos legales antes mencionados: en el caso de la Gestión de Riesgo de Desastres Correctiva, se identificó que el Art. 80 de la LGUC incorpora mecanismos correctivos tanto de prevención como de mitigación, orientados a reducir el riesgo ya existente en determinado territorio mediante el traslado de población vulnerable hacia sectores donde dicha vulnerabilidad y el impacto de las amenazas naturales sea menor. El artículo 2.1.17 OGUC complementa y precisa las disposiciones contenidas en los artículos 60, 80 y 105 de la LGUC, con lo cual incorpora también medidas de GRD correctiva (Art. 80) (Cuadro 3).

Cuadro 3

Abordaje de GRD en normas nacionales

\begin{tabular}{|l|c|c|c|c|c|}
\hline \multirow{2}{*}{ Nombre de Texto Normativo / Tipo de GRD } & \multicolumn{4}{|c|}{ Ámbitos GRD abordados } \\
\cline { 2 - 6 } & \multicolumn{2}{|c|}{$\begin{array}{c}\text { GRD } \\
\text { Correctiva }\end{array}$} & $\begin{array}{c}\text { GRD } \\
\text { Prospectiva }\end{array}$ & \multicolumn{2}{c|}{$\begin{array}{c}\text { GRD } \\
\text { Reactiva }\end{array}$} \\
\cline { 2 - 6 } & PREV & MIT & PREP & RESP & $\begin{array}{c}\text { RE- } \\
\text { CUP }\end{array}$ \\
\hline Constitución Política de la República de Chile & 0 & 0 & 0 & 1 & 1 \\
\hline Ley de los Estados de Excepción & 0 & 0 & 0 & 1 & 1 \\
\hline Ley de Reconstrucción & 0 & 0 & 0 & 1 & 1 \\
\hline Ley de Sismos y Catástrofes & 0 & 0 & 0 & 1 & 1 \\
\hline Ley General de Urbanismo y Construcciones & 1 & 1 & 1 & 0 & 0 \\
\hline $\begin{array}{l}\text { Ordenanza General de Urbanismo y } \\
\text { Construcciones }\end{array}$ & 1 & 1 & 1 & 0 & 0 \\
\hline Total & $\mathbf{2}$ & $\mathbf{2}$ & $\mathbf{2}$ & $\mathbf{4}$ & $\mathbf{4}$ \\
\hline
\end{tabular}

Fuente: Elaboración propia (2016)

En el caso de la Gestión de Riesgo de Desastres Prospectiva, se identificaron los artículos $60^{\circ}, 105^{\circ}, 116^{\circ}$ bis $D$ y $166^{\circ}$ de la LGUC como aquellos que incorporan medidas que buscan evitar la generación de un riesgo a futuro. El artículo $60^{\circ}$ refiere a la posibilidad de los PRC de señalar terrenos no edificables en base a su naturaleza y ubicación; el artículo $105^{\circ}$ refiere al diseño de las obras de urbanización y edificación, destacando entre sus estándares las características que deberán tener tanto las edificaciones que se encuentren en áreas de riesgo natural, como obras de urbanización para mitigar los riesgos y facilitar evacuación; el artículo $116^{\circ}$ bis $\mathrm{D}$ por su parte otorga la potestad a la OGUC de regularizar edificaciones localizadas en zonas afectadas por catástrofe; y el artículo $166^{\circ}$, condiciona los permisos de ampliación de viviendas sociales a las disposiciones de los PRC respecto de las áreas de riesgo y protección. En el caso de la OGUC, se identificó que el artículo 2.1.17 incorpora medidas de GRD prospectiva al definir las condiciones para establecer áreas restringidas al desarrollo urbano dentro de un IPT, las cuales pueden constituirse en "zonas no edificables" o "áreas de riesgo" según el caso. Para el caso de las áreas de riesgo se contempla la posibilidad de permitir su ocupación siempre que la solicitud del proyecto se acompañe por un estudio fundado de riesgo donde se propongan medidas orientadas a mitigar los efectos del riesgo existente. 
Finalmente, en el caso de la Gestión de Riesgo de Desastres Reactiva, se identifican los artículos $1^{\circ} \mathrm{y}$ del $39^{\circ}$ al $45^{\circ}$ que norman las situaciones de excepción como emergencias y calamidades públicas; como alcance a dichos artículos se identifican los artículos $5^{\circ}, 7^{\circ}$ y $9^{\circ}$ de la Ley de Estados de Excepción (Ley 18.415), que definen el actuar de las distintas reparticiones del Estado ante la declaración de un estado de emergencia o catástrofe; y se adicionan las disposiciones contenidas en la Ley 16.282 de Sismos y Catástrofes, que posibilitan aprobar PRC comunales e intercomunales mediante decretos supremos, en aquellas zonas afectadas por catástrofes. En vista de lo anterior es posible concluir que tanto la Constitución como la Ley de Estados de Excepción albergan medidas orientadas a garantizar una respuesta rápida y efectiva por parte del Estado ante una catástrofe, así como una pronta recuperación post-desastre de la localidad o sector afectado.

En vista de los resultados presentados, se puede concluir que existe una distribución bastante homogénea de los tres tipos de GRD entre las 6 normas analizadas, siendo aquellas pertenecientes al 1er y $2^{\text {do }}$ nivel jerárquico las que acumulan más medidas de GRD reactiva, y la LGUC y OGUC las únicas normas que abordan medidas prospectivas y correctivas, lo que deja en manos del MINVU la responsabilidad de incorporar este tipo de medidas dentro de los procesos de planificación y desarrollo urbano llevados a cabo en el país.

\section{Actos administrativos y abordaje del riesgo}

En el caso de los actos administrativos, que suman un total de 50 documentos entre los 4 tipos revisados, fue posible identificar lo siguiente:

- De 24 Boletines CGR: 2 mencionan riesgos asociados a inundación o incendios, 3 refieren a desastres de origen natural, 1 a desastres de origen antrópico y 4 a desastres de ambos orígenes, sólo 1 fue emitido posterior a un desastre y 1 refiere a zonas de protección o uso restringido.

- De 11 circulares DDU: 3 mencionan riesgos asociados a terremoto, tsunami o incendios; 1 refiere a desastres de origen natural, 1 a desastres de origen antrópico y 9 a desastres de ambos orígenes, 9 fueron emitidas posterior a un desastre y 10 refieren a zonas de protección o uso restringido.

- De 15 dictámenes CGR: 5 mencionan riesgos asociados a deslizamientos, erupciones volcánicas, y terremotos; 7 refieren a desastres de origen natural y 6 a desastres de ambos orígenes, 4 fueron emitidas posterior a un desastre y 1 refiere a zonas de protección o uso restringido (Cuadro 4).

Cuadro 4

Abordaje del riesgo en actos administrativos

\begin{tabular}{|l|c|c|c|c|c|}
\hline $\begin{array}{l}\text { Tipo de } \\
\text { Acto }\end{array}$ & $\begin{array}{c}\text { Menciona } \\
\text { Riesgos }\end{array}$ & Tipos de Riesgo & $\begin{array}{c}\text { Tipo de } \\
\text { Desastre }\end{array}$ & $\begin{array}{c}\text { Emitida } \\
\text { posterior a } \\
\text { un desastre }\end{array}$ & $\begin{array}{c}\text { Refiere a zonas } \\
\text { de protección o } \\
\text { uso restringido }\end{array}$ \\
\hline $\begin{array}{l}\text { Boletín } \\
\text { CGR }\end{array}$ & $\begin{array}{c}\text { SI (3) } \\
\text { NO (21) }\end{array}$ & $\begin{array}{c}\text { Inundación (1) } \\
\text { Incendios (1) } \\
\text { Ninguno (22) }\end{array}$ & $\begin{array}{c}\text { Natural (3) An- } \\
\text { trop. (1) Ambos (4) } \\
\text { Ninguno (16) }\end{array}$ & $\begin{array}{c}\mathrm{SI}(1) \\
\text { NO (23) }\end{array}$ & $\begin{array}{c}\mathrm{SI}(1) \\
\mathrm{NO}(23)\end{array}$ \\
\hline
\end{tabular}




\begin{tabular}{|l|c|c|c|c|c|}
\hline $\begin{array}{l}\text { Tipo de } \\
\text { Acto }\end{array}$ & $\begin{array}{c}\text { Menciona } \\
\text { Riesgos }\end{array}$ & Tipos de Riesgo & $\begin{array}{c}\text { Tipo de } \\
\text { Desastre }\end{array}$ & $\begin{array}{c}\text { Emitida } \\
\text { posterior a } \\
\text { un desastre }\end{array}$ & $\begin{array}{c}\text { Refiere a zonas } \\
\text { de protección o } \\
\text { uso restringido }\end{array}$ \\
\hline $\begin{array}{l}\text { Circular } \\
\text { DDU }\end{array}$ & $\begin{array}{c}\text { SI (5) } \\
\text { NO (6) }\end{array}$ & $\begin{array}{c}\text { Terremoto(1) Tsunami } \\
\text { (1) Incendios (1) } \\
\text { Todos (8) }\end{array}$ & $\begin{array}{c}\text { Natural (1) An- } \\
\text { trop. (1) Ambos } \\
(9)\end{array}$ & $\begin{array}{c}\text { SI (9) } \\
\text { NO (2) }\end{array}$ & SI (10) \\
NO (1)
\end{tabular}

Fuente: Elaboración propia (2016)

Ahora bien al revisar los ámbitos de la GRD abordados por los distintos actos administrativos previamente listados, se pudo identificar lo siguiente (Cuadro 5):

En términos de los actos que incorporan medidas de Gestión de Riesgo de Desastres Correctiva, se identificaron 3 boletines de CGR, 3 circulares DDU y 6 dictámenes de CGR que refieren a temas asociados a dicho tipo de GRD. En el caso de las circulares revisadas se observa que predominan aclaratorias respecto a la correcta aplicación de los IPT, en particular los PRC, en lo concerniente a medidas relacionadas con presencia de riesgo. Por su parte, los actos emitidos por la Contraloría suelen reafirmar la necesidad de dar cumplimiento a lo establecido en el artículo 2.1.17 de la OGUC.

En el caso de los actos que incorporan medidas de Gestión de Riesgo de Desastres Prospectiva, se identificaron 3 boletines de CGR, 3 circulares DDU y 6 dictámenes de CGR que refieren a temas asociados a dicho tipo de GRD. En las circulares revisadas se observan aclaratorias respecto a la necesidad de incorporar estudios fundados de riesgo dentro de los contenidos de la memoria explicativa, y áreas restringidas al desarrollo urbano dentro de la ordenanza local. En esa misma línea, los boletines CGR revisados se pronuncian sobre la necesidad de cumplir con los requisitos que establece la ley respecto al emplazamiento de un proyecto en una zona de riesgo; y los dictámenes generales de CGR se alinean a dicha función al abstenerse de tomar razón de decretos de promulgación de modificaciones de PRC cuando éstos no fijan áreas de riesgo o las fijan de forma inadecuada y poco fundada.

En el caso de los actos que incorporan medidas de Gestión de Riesgo de Desastres Reactiva, se identificaron 4 boletines de CGR, 8 circulares DDU y 6 dictámenes de CGR que refieren a temas asociados a dicho tipo de GRD. A partir de los actos revisados se observa que en su mayoría contienen disposiciones y resoluciones orientadas a normar o realizar aclaratorias sobre consultas originadas producto de procesos de reconstrucción y recuperación post-desastre. 
Cuadro 5

Abordaje de GRD en actos administrativos

\begin{tabular}{|l|c|c|c|c|c|c|}
\hline \multirow{2}{*}{$\begin{array}{l}\text { Tipo de Acto / } \\
\text { Tipo de GRD }\end{array}$} & \multicolumn{2}{|c|}{$\begin{array}{c}\text { GRD } \\
\text { Correctiva }\end{array}$} & $\begin{array}{c}\text { GRD } \\
\text { Prospectiva }\end{array}$ & GRD Reactiva & \multirow{2}{*}{ Ninguno } & $\begin{array}{c}\text { Total } \\
\text { Actos }\end{array}$ \\
\cline { 2 - 7 } & PREV & MIT & PREP & RECUP (y RESP) & & 18 \\
\hline Boletines CGR & 3 & 0 & 3 & $3(2)$ & 24 \\
\hline Circulares DDU & 3 & 0 & 3 & $8(0)$ & 0 & 11 \\
\hline Dictámenes CGR & 6 & 0 & 6 & $6(1)$ & 3 & 15 \\
\hline TOTAL & $\mathbf{1 2}$ & $\mathbf{0}$ & $\mathbf{1 2}$ & $\mathbf{1 7}$ & $\mathbf{2 1}$ & $\mathbf{5 0}$ \\
\hline
\end{tabular}

Fuente: Elaboración propia (2016)

A modo de cierre, luego de analizar los 50 actos se puede concluir que el foco de los mismos se encuentra puesto en GRD reactiva (17), seguido por la GRD correctiva (12) y la GRD prospectiva (12), siendo de igual relevancia destacar el hecho de que 21 de los 50 actos no aborden ningún tipo de GRD.

\section{Gestión del riesgo en instrumentos de planificación territorial intercomunal y comunal}

Para poder evaluar y analizar la inclusión de la gestión del riesgo por parte de los instrumentos de planificación territorial, interesa primero comprender el estado de situación de los IPT en Chile, específicamente los Planes Reguladores Comunales (PRC). En ese sentido, existen dos perspectivas distintas sobre el mismo asunto: Valencia (2015) plantea que un cuarto de las comunas no cuenta con plan regulador, y sólo el $34 \%$ del total está vigente; afirmación que se basa en que, de un total de 346 comunas, sólo 117 cuentan con un PRC vigente y el resto se distribuye entre 144 comunas con planes en proceso de modificación, 75 en proceso de formulación y 10 que carecen de este instrumento. Sin embargo, desde la perspectiva de la División de Desarrollo Urbano y la Comisión de Estudios Habitacionales y Urbanos (CEHU) del MINVU, el 75\% (261) de las comunas tienen planes vigentes y sólo el 25\% (85) de éstas se encuentran sin plan por los momentos (MINVU, 2016) (Cuadro 6).

Cuadro 6

PRC vigentes y no vigentes en Chile

\begin{tabular}{|l|c|c|c|c|}
\hline \multirow{2}{*}{ PRC } & \multicolumn{2}{|c|}{ Según Valencia } & \multicolumn{2}{c|}{ Según MINVU } \\
\cline { 2 - 5 } & Cantidad & \% & Cantidad & \% \\
\hline Vigentes & 117 & 33,8 & 261 & 75 \\
\hline No vigentes & 229 & 66,2 & 85 & 25 \\
\hline TOTAL & $\mathbf{3 4 6}$ & $\mathbf{1 0 0}$ & $\mathbf{3 4 6}$ & $\mathbf{1 0 0}$ \\
\hline
\end{tabular}

Fuente: Elaboración propia en base a Valencia (2015) y Observatorio MINVU (2016) 
Independientemente de los panoramas antes descritos, y de las diferencias de interpretación existentes respecto al número de comunas que cuentan con plan regulador o carecen de este, la ausencia absoluta o falta de actualización de los PRC es la consecuencia de procesos de elaboración y modificación complejos, burocráticos y lentos que demoran en promedio 7 años según lo expresa Santa María (2015); de la ausencia de equipos técnicos capacitados en un porcentaje importante de las municipalidades; y de la carencia de recursos económicos suficientes por parte de las administraciones locales para abordar el desarrollo de dichos procesos, esto debido a que la elaboración de un plan regulador puede costar desde $\$ 80$ millones a $\$ 250$ millones en función de los estudios que incluya (Valencia, 2015).

El marco normativo que regula la modificación de los PRC establece un proceso que resulta tan engorroso y lento como el asociado a la elaboración de dichos IPT, con lo cual la posibilidad de realizar un ajuste eficiente a éstos posterior a la ocurrencia de una catástrofe para adaptarlos a la nueva realidad existente es prácticamente nula. Coincidentemente, una de las conclusiones del estudio realizado por Columbia University en conjunto con Chile Fund plantea a modo de recomendación:

Que los Planes Reguladores debieran considerar la posibilidad de una retroalimentación futura en caso de catástrofes, pues las prioridades de desarrollo urbano pueden cambiar de la noche a la mañana con un terremoto; en ese sentido, los IPT debieran contar con mecanismos que permitieran su adaptabilidad ante situaciones como un terremoto (Latin Lab, GSAPP Columbia University y Santiago Research Cell 2015: 143)

\section{Casos de estudio comunales e inclusión de la GRD en sus IPT}

Ahora bien, a efectos de poder evaluar la inclusión de la GRD dentro de los IPT que regulan el desarrollo urbano en el ámbito comunal, y de acuerdo a lo planteado al inicio del artículo respecto a la metodología empleada para esta investigación, se tiene que en el caso de las comunas chilenas (Muestra 2), se llevaron a cabo 3 etapas de selección:

En la primera se establecieron 3 condicionantes como criterios de selección: que la comuna hubiese sido afectada por un desastre entre los años 2005 y 2015; y que dicho desastre fuese de origen natural, por ser éstos lo que ocurren con mayor frecuencia. Esto permitió obtener un listado de 12 comunas presentado en el Cuadro 7 siguiente.

\section{Cuadro 7}

Desastres Naturales ocurridos en Chile en el período 2005 - 2015 y comunas seleccionadas en el estudio.

\begin{tabular}{|l|c|c|c|c|c|}
\hline Fecha & Desastre & Causa & $\begin{array}{c}\text { Comuna a } \\
\text { estudiar }\end{array}$ & $\begin{array}{c}\text { Etapa de } \\
\text { Selección 2 }\end{array}$ & $\begin{array}{c}\text { Etapa de } \\
\text { Selección 3 }\end{array}$ \\
\hline $13 / 06 / 2005$ & Terremoto & Falla & Iquique & $\mathrm{SI}$ & $\mathrm{NO}$ \\
\hline $11 / 07 / 2006$ & Deslizamiento & $\begin{array}{c}\text { Sistema Frontal/ } \\
\text { Lluvias }\end{array}$ & Chiguayante & $\mathrm{SI}$ & $\mathrm{SI}$ \\
\hline $14 / 11 / 2007$ & Terremoto & Falla & Tocopilla & $\mathrm{SI}$ & $\mathrm{SI}$ \\
\hline
\end{tabular}




\begin{tabular}{|l|c|c|c|c|c|}
\hline Fecha & Desastre & Causa & $\begin{array}{c}\text { Comuna a } \\
\text { estudiar }\end{array}$ & $\begin{array}{c}\text { Etapa de } \\
\text { Selección 2 }\end{array}$ & $\begin{array}{c}\text { Etapa de } \\
\text { Selección 3 }\end{array}$ \\
\hline 02/05/2008 & Erupción & Actividad Volcánica & Chaitén & $\mathrm{SI}$ & $\mathrm{SI}$ \\
\hline $27 / 02 / 2010$ & $\begin{array}{c}\text { Terremoto y } \\
\text { tsunami }\end{array}$ & Falla & Constitución & $\mathrm{SI}$ & $\mathrm{NO}$ \\
\hline $04 / 06 / 2011$ & Erupción & Actividad Volcánica & Puyehue & NO & NO \\
\hline $12 / 02 / 2012$ & Aluvión & Lluvias & $\begin{array}{c}\text { San Pedro de } \\
\text { Atacama }\end{array}$ & NO & NO \\
\hline $11 / 03 / 2012$ & Inundación & Lluvias & Punta Arenas & NO & NO \\
\hline $01 / 04 / 2014$ & $\begin{array}{c}\text { Terremoto y } \\
\text { tsunami }\end{array}$ & Falla & lquique & NO & NO \\
\hline $25 / 03 / 2015$ & Aluvión & Temporal/Lluvias & Chañaral & NO & NO \\
\hline $22 / 04 / 2015$ & Erupción & Actividad Volcánica & Puerto Montt & NO & NO \\
\hline $16 / 09 / 2015$ & $\begin{array}{c}\text { Terremoto y } \\
\text { tsunami }\end{array}$ & Falla & Illapel & NO & NO \\
\hline
\end{tabular}

Fuente: Elaboración propia en base a LA RED (2016)

Cabe destacar que la mayoría de los desastres naturales identificados generaron impactos negativos en más de una comuna, por lo que en dichos casos se decidió asociar cada desastre a la comuna que mayores daños hubiese presentado producto de dicho desastre. La segunda etapa de selección consistió, al igual que la primera, en la aplicación del siguiente conjunto de criterios de selección: que hubiesen transcurrido al menos 2 años desde la ocurrencia del desastre; y que se hubiese decretado "Zona de Catástrofe" producto del desastre, debido a que con ello se agiliza el proceso de formulación o modificación de los IPT. Esto permitió reducir el listado de 12 a 5 comunas.

La tercera y última etapa de selección tuvo como base elegir comunas asociadas a desastres naturales de origen distinto, que abarcaran múltiples sectores del país (Norte, Centro, Sur) y que su estudio contribuyera al conocimiento por haber sido poco investigadas. En base a ello se decidió elegir a las comunas de Chiguayante, Tocopilla y Chaitén como casos de estudio.

El primer caso de estudio corresponde a la comuna de Chiguayante, elegida por el deslizamiento de tierra que la afectó durante el sistema frontal de julio de 2006. Dicho evento generó un saldo a nivel comunal de 10 fallecidos, 5000 afectados, 500 damnificados, 21 albergados y 6 viviendas destruidas, lo que llevó a la declaración de zona de catástrofe el mismo día de la ocurrencia del desastre. Teniendo lo anterior como contexto, se procedió a realizar una revisión de los IPT que aplican en la comuna de Chiguayante para así identificar su abordaje respecto del riesgo. En ese sentido, de las 5 escalas abordadas por los IPT sólo se encuentran vigentes un instrumento metropolitano y uno comunal, los que datan de antes del evento y fueron modificados después del mismo, hecho que permite poder constatar si dichas modificaciones respondieron a un proceso de aprendizaje. 
En lo referente al Plan Regulador Metropolitano de Concepción (PRMC), se tiene que el mismo recibió 9 modificaciones entre el 2005 y 2015 luego de ser promulgado en 2003. De éstas, sólo interesan a efectos de esta investigación dos de ellas, por ser las únicas con injerencia sobre la comuna en cuestión y por los temas que abordan. Sin embargo, ninguna de ellas incorpora regulación o medida alguna orientada a gestionar el riesgo por desastre de deslizamiento existente en Chiguayante, por lo que las únicas medidas de GRD que incorpora el PRMC son las contenidas en las 4 zonas asociadas a amenazas naturales que contiene el plan desde su origen.

En el caso del Plan Regulador Comunal de Chiguayante, aprobado en 2003, se tiene que éste incorpora 6 áreas especiales que contienen medidas de preparación y mitigación orientadas a la implementación de una GRD correctiva por enfocarse en reducir el riesgo por inundación y deslizamiento ya existente mediante zonas buffer y defensas fluviales. En la década estudiada, el PRC en cuestión recibió 5 ajustes entre enmiendas y modificaciones, de los cuales sólo 3 guardan relación con la GRD. De éstas, sólo las modificaciones del 2006 y 2009 están motivadas por la necesidad de incluir o modificar determinadas normas urbanísticas para incorporar mecanismos de GRD prospectivos y correctivos. La primera de ellas se encarga de normar los estudios de riesgo solicitados para desarrollar un proyecto; la segunda modifica ciertas normas urbanísticas de una zona con riesgo de remoción en masa haciendo más restrictivas las condiciones de desarrollo, por lo que se puede asumir que dicha modificación se origina de un proceso de aprendizaje sobre los efectos negativos del deslizamiento ocurrido 3 años antes; la tercera mantiene declaratorias de utilidad pública asociadas a zonas buffer de resguardo frente a inundación por desborde de cauces.

El segundo caso de estudio corresponde a la comuna de Tocopilla, elegida por el terremoto que la afectó en noviembre de 2011. Dicho evento generó un saldo de 2 fallecidos, 4.081 albergados y 17.363 damnificados de los cuales el $68 \%$ de los damnificados y el $43 \%$ de las viviendas destruidas pertenecían a la comuna en cuestión, llevando a la declaración de zona de catástrofe el mismo día de la ocurrencia del desastre. Teniendo lo anterior como contexto, se procedió a realizar una revisión de los IPT que aplican en la comuna de Tocopilla para así identificar su abordaje respecto del riesgo. En ese sentido se observó que de las 5 escalas abordadas por los IPT, sólo existe un instrumento comunal que se encontraba vigente antes del evento y que fue modificado después del mismo, permitiendo constatar si dichas modificaciones responden a un proceso de aprendizaje.

Este es el caso del Plan Regulador Comunal de Tocopilla el cual, si bien fue aprobado en 1988, en el año 2001 recibió una actualización que implicó cambio de nomenclaturas y la creación de 8 zonas asociadas a amenazas naturales, que mantuvieron un enfoque en medidas de GRD correctiva al establecer zonas buffer en torno a zonas de alto riesgo como cauces de quebradas y borde costero. Sin embargo, también se adicionaron dos zonas de restricción frente a amenazas naturales, las cuales incorporaron medidas de GRD prospectivas al establecer zonas de restricción y protección para evitar la generación del riesgo. En la década estudiada, el PRC en cuestión recibió 3 ajustes entre seccionales y modificaciones, de los cuales sólo 1 guarda relación con la GRD. Dicha modificación, sin embargo, tomó una zona industrial y la transformó en residencial perdiéndose así las medidas de mitigación que dicha zona establecía respecto a la amenaza de tsunami. De igual forma, esta modificación no fue aprobada mediante el artículo 27 de la Ley de 
Sismos y Catástrofes, por lo cual se presume que no incluyó ningún aprendizaje proveniente del terremoto ocurrido un año antes.

Finalmente es posible plantear que el PRC de Tocopilla contenía en sus disposiciones mecanismos de GRD correctiva orientados a disminuir el riesgo existente y evitar futuros desastres. Sin embargo, con la actualización de 2001 y las modificaciones subsiguientes, dicho enfoque de GRD se fue viendo disminuido poco a poco, al perderse las medidas que buscaban mitigar el riesgo.

El tercer y último caso de estudio corresponde a la comuna de Chaitén, elegida por la erupción volcánica que la afectó en mayo de 2008. Dicho evento generó un saldo de 4.400 evacuados y la inundación del $90 \%$ de la ciudad de Chaitén llevando a la declaración de zona de catástrofe el 14 de mayo del mismo año. Teniendo lo anterior como contexto, se procedió a realizar una revisión de los IPT que aplican en la comuna de Chaitén para así identificar su abordaje respecto del riesgo. En ese sentido se observó que de las 5 escalas abordadas por los IPT, no existe ningún instrumento comunal que estuviera vigente antes del evento y fuese modificado después del mismo, con lo cual no es posible constatar si hubo alguna modificación producto de un proceso de aprendizaje. En el caso del Límite Urbano de Chaitén, aprobado en 1987, se tiene que el mismo admite sin restricciones todo tipo de usos dentro de él, con la excepción de los terrenos adyacentes al Río Blanco, donde se prohíbe el uso residencial. En función de ello es posible concluir que en dicha comuna no ha ocurrido un aprendizaje a partir del desastre, debido a que 11 años después la misma carece de un IPT aprobado. Ello es muestra de las muchas trabas y desinterés existente por parte de los distintos entes que componen el Estado, respecto de la importancia de generar un IPT que permita regular adecuadamente el territorio comunal, así como incluir mecanismos de GRD dentro del mismo para evitar la generación de desastres futuros.

\section{Discusión y Conclusiones}

Un estudio realizado por Platt y So (2016) a diferentes países colocan al país como el más exitoso en la recuperación post-desastres, planteando que "varios factores contribuyeron al éxito de Chile: un fuerte liderazgo a nivel nacional y local; la utilización de las iniciativas e instituciones existentes; la flexibilidad para adaptar los programas a lo largo del tiempo; un personal técnico fuerte; una economía robusta; y voluntad política". Pero a pesar de lo anterior ¿Se incorporan los aprendizajes a partir de los desastres que afectan continuamente a Chile, sobre todo en los últimos años, en las normas e instrumentos que regulan el desarrollo urbano?

Para responder a dicho cuestionamiento es importante primero indicar que el punto en común de todos los acuerdos e iniciativas internacionales en las que participa Chile se relacionan con la necesidad de generar un intercambio entre diferentes naciones, de los conocimientos y aprendizajes que cada una ha adquirido a partir de los desastres naturales a los que se ha tenido que enfrentar. En este sentido, Chile ha adquirido durante toda su historia reciente, un amplio conocimiento y experiencia en el manejo y la gestión del riesgo de terremotos, por la frecuencia y magnitud con la que dichos eventos naturales se presentan en su territorio. Lo anterior le ha significado al país, la modificación continua de sus códigos de construcción y sistemas de fiscalización que garanticen el cumplimiento de las normas orientadas a la sismo resistencia, pero también ha impactado el ámbito de preparación y de respuesta y reacción por parte de la población 
y de las diversas instituciones del Estado ante la ocurrencia de eventos sísmicos. Sin embargo frente a otros eventos de origen natural como remociones en masa, inundaciones, erupciones volcánicas y tsunamis, los aprendizajes que la nación puede adquirir de sus vecinos regionales son tan importantes como aquellos que puede extraer de sus propias vivencias, razón por la cual es de tanta relevancia que dichos intercambios entre naciones latinoamericanas y de otros continentes sean un hecho continuo y constante.

Ahora bien, colocando el foco en el objeto que guía la presente investigación, se tiene entonces que a partir del análisis realizado a las 6 normas de alcance nacional mencionadas en secciones previas, fue posible identificar el predominio de mecanismos de gestión de riesgo de desastres del tipo reactiva dentro de sus disposiciones, hecho que confirma la hipótesis de este artículo respecto del foco que coloca el Estado chileno en la situación post-desastre. Lo anterior se ve reforzado por el análisis comparado de las pirámides jurídicas urbanísticas de 2005 y 2015, que evidencia un aumento en su complejidad traducido en una mayor presencia de actos administrativos y modificaciones al marco legal nacional que rige ante la ocurrencia de un desastre, lo que está fuertemente enfocado en mecanismos de GRD reactivos.

De igual forma se observa que dentro del marco normativo ya estudiado, la Ley General de Urbanismo y Construcciones y su ordenanza (OGUC) desempeñan un rol central en la configuración y regulación del desarrollo urbano en el país al ser los encargados de normar la formulación y aplicación de los distintos IPT orientados a la urbanización adecuada del territorio. En este sentido, ambos cuerpos normativos son los únicos que incorporan, aunque de forma insuficiente, mecanismos de GRD correctiva y prospectiva.

Por su parte, el análisis de los actos administrativos permitió concluir que las circulares DDU MINVU son las únicas que suelen ser emitidas de forma posterior a un desastre, y de igual forma, las que mayor mención hacen a temas de riesgo y desastre, con lo cual son el principal acto que permite al Estado la incorporación de aprendizajes obtenidos a partir de desastres. Otra reflexión deriva del análisis de los dictámenes de Contraloría, relacionada con la presencia recurrente de errores en los PRC aprobados, asociados a la inclusión de Estudios Fundados de Riesgo que no cumplen con las disposiciones establecidas en el Art. 2.1.17 OGUC. Lo anterior devela una falta de rigurosidad por parte de los actores públicos y privados en torno a la elaboración de este tipo de estudios.

Pasando al análisis de los casos de estudio y los IPT comunales, se extrae que a pesar de existir la posibilidad de simplificar la tramitación de un PRC mediante un decreto de zona de catástrofe, en ninguno de los casos las autoridades competentes hicieron uso de dicho beneficio para incorporar aprendizajes en los IPT correspondientes. Es así como en el caso del PRM de Concepción se observó que si bien existe una intención por reconocer las zonas de riesgo natural, el Plan delega la responsabilidad de una adecuada regulación en los PRC. En el caso de los planes reguladores de las tres comunas analizadas, la comuna de Chiguayante fue la que presentó el mayor número de modificaciones, las cuales sin embargo no son muestra de la intención por adecuar los instrumentos a los nuevos riesgos detectados, sino que denotan un ritmo alto de modificación de sus instrumentos por parte del municipio. La situación anterior se produce, según lo constatado por Moris et. al. (2018), por la ausencia de definiciones claras en la legislación y reglamentación nacional respecto de los tipos de amenazas y forma de evaluación para normar usos en los IPT 
de Chile; lo que deviene en implementación de procesos modificatorios de IPTs poco uniformes como es el caso de los eventos aluvionales de Chañaral y Diego de Almagro de marzo de 2015, situación confirmada por Jaque (2017) para el caso de Coronel.

En vista de dichos resultados, es posible concluir que la influencia que han tenido los desastres naturales ocurridos en Chile entre 2005 y 2015, en la incorporación de la GRD dentro de normativas nacionales e IPT comunales ocurre de forma diferenciada según la escala de la que se trate. En el ámbito nacional se visualiza la existencia de una búsqueda continua, y cada vez más intensa, por incorporar o generar nuevos mecanismos de gestión del riesgo de desastres dentro de las normativas existentes. Sin embargo, los plazos de ejecución de dichos ajustes son bastante largos y las velocidades de implementación lentas, razón por la cual muchas de las iniciativas actualmente en desarrollo por parte del Estado en este sentido, pueden ser adecuadas pero llegar después de un futuro desastre (Ej. Modificación Art. 2.1.17 OGUC). Adicionalmente el foco del trabajo legislativo y normativo está en la GRD reactiva, por sobre otros ámbitos que permitirían ser más efectivos en evitar pérdidas humanas y económicas. Estos resultados son consistentes con los planteados por Tapia (2014) en relación a la historia normativa post terremotos, quien concluye que se han creado, mejorado y aplicado según la experiencia acumulada, y lo indicado por Camus et. al. (2016) respecto del carácter reactivo de las medidas de la GRD en Chile.

En el ámbito comunal, por el contrario, si bien existen mecanismos que agilizan los plazos y simplifican la burocracia para la formulación o modificación de sus IPT, también se identifica una mayor descoordinación en torno a la necesidad de otorgar prioridad a la incorporación de aquellos aprendizajes obtenidos a partir de la ocurrencia de desastres, lo que se expresa en la continua recurrencia de los mismos. Cada vez son más las comunas preocupadas por mantener sus planes reguladores actualizados y vigentes, ocurre que al momento de realizarse dichos procesos de actualización, no concurren ni participan todos los actores e instituciones del Estado que tienen influencia en el territorio comunal, desaprovechándose la oportunidad que dicho momento constituye para el intercambio de visiones e información en función de un objeto común: la comuna. Acá es interesante el caso de Chaitén, respecto de que a pesar de lo grave de su situación, no se avanzó o se aprendió muy poco en términos normativos, tal como lo indica Tapia (2015) y es confirmado en este estudio.

Finalmente pareciera ser necesario revisar los mecanismos de actualización o de implementación de IPT una vez ocurrido los desastres, para que estos permitan adaptarse a las nuevas realidades $\mathrm{o}$ aprendizajes que se generan.

\section{Referencias:}

ALDUNCE, P.; BEILIN, R.; HANDMER, J. y HOWDEN, M. Framing disaster resilience: The implications of the diverse conceptualisations of "bouncing back". Disaster Prevention and Management: An International Journal. 2014, Vol. 23, Nº 3. p. 252-270. Disponible en Internet: https://doi.org/10.1108/ dpm-07-2013-0130.

ARENAS, F.; LAGOS, M. e HIDALGO, R. Los riesgos naturales en la planificación territorial. Temas de la agenda pública, Centro de Políticas Públicas UC. 2010, Año 5, № 39. p. 1-11. 
BAJRACHARYA, B.; CHILDS, I. y HASTINGS, P. Climate change adaptation through land use planning and disaster management: Local government perspectives from Queensland. In: 17th Pacific Rim Real Estate Society Conference. Climate change and property: Its impact now and later. Gold Coast, Australia, 16 al 19 enero de 2011. Disponible en Internet: http://prres.net/papers/Bajracharya_Childs_Hastings_Climate_change_disaster_management_and_land_use_planning.pdf

BEATLEY, T. Planning for Coastal Resilience: Best Practices for Calamitous Times. Washington: Island Press, 2009.

BRAIN, I. y MORA, P. Emergencia y reconstrucción: el antes y después del terremoto y tsunami del $27 \mathrm{~F}$ en Chile. Aprendizajes en materia habitacional, urbana y de seguros. 1ra. ed. Santiago, Chile: Centro de Políticas Públicas UC y Fundación MAPFRE, 2012. Disponible en Internet: https:// politicaspublicas.uc.cl/wp-content/uploads/2015/02/emergencia-y-reconstruccion-el-antes-y-eldespues-del-terremoto-y-tsunami-del-27f.pdf

BOZZA, A.; ASPRONE, D. y MANFREDI, G. Developing an integrated framework to quantify resilience of urban systems against disasters. Natural Hazards, 2015, Vol. 78, № 3. p. 1729-1748. Disponible en Internet: https://doi.org/10.1007/s11069-015-1798-3

BUSTOS, M.; HERRERA, J. y LABRÍN, S. Subsecretario del Interior llama a los alcaldes a trabajar en planes reguladores de las comunas. Santiago, Chile, 31 de Marzo de 2015. p. 2. (En sección: Temas de Hoy, Diario La Tercera). Disponible en Internet: http://www.plataformaurbana.cl/ archive/2015/03/31/subsecretario-del-interior-Ilama-a-los-alcaldes-a-trabajar-en-planes-reguladores-de-las-comunas/

CAMACHO, A. Managing Adaptation: Developing a Learning Infrastructure in the United States Federal System. En: ALBRECHT, E.; SCHMIDT, M.; MIßLER-BEHR, M. y SPYRA, S. Implementing Adaptation Strategies by Legal, Economic and Planning Instruments on Climate Change. Berlín: Springer, 2014. p. 41-54. Disponible en Internet: https://doi.org/10.1007/978-3-540-77614-7

CAMUS, P.; ARENAS, F.; LAGOS, M. y ROMERO, A. Visión histórica de la respuesta a las amenazas naturales en Chile y oportunidades de gestión del riesgo de desastre. Revista de Geografía Norte Grande, 2016, № 64, p. 9-20. Disponible en Internet: https://dx.doi.org/10.4067/S071834022016000200002

CHUQUISENGO, O. Guía de Gestión de Riesgos de Desastres. Aplicación Práctica. Lima: Soluciones Prácticas, 2011. Disponible en Internet: http://cridlac.org/digitalizacion/pdf/spa/doc19058/ doc19058.htm

CIENFUEGOS, R. Centro de Investigación para la Gestión Integrada de Desastres. In: Seminario Chile Resiliente: Planificación y Gestión de Riesgos de Desastres Naturales. Santiago, Chile, 4 septiembre de 2015.

CONTRERAS, Y. y BELTRAN, M. Reconstruir con capacidad de resiliencia: El casco histórico de la ciudad de Constitución y el sitio del desastre del terremoto y tsunami del 27 de febrero 2010. Re- 
vista INVI, 2015, Vol. 30, N 83. p. 79-115. Disponible en Internet: http://revistainvi.uchile.cl/index. php/INVI/article/view/826.

CONTRUCCI, P. Perfeccionamiento a la normativa urbana para la reducción del riesgo de desastres. In: Seminario Chile Resiliente: Planificación y Gestión de Riesgos de Desastres Naturales. Santiago, Chile, 4 septiembre de 2015.

CORDERO, E. El derecho urbanístico: los instrumentos de planificación territorial y el régimen jurídico de los bienes públicos. Revista de Derecho de la Pontificia Universidad Católica de Valparaíso, 2007, No 29. p. 269-298. Disponible en Internet: https://scielo.conicyt.cl/scielo.php?script=sci_arttext\&pid=S0718-68512007000100009

COTE, M. Climate Adaptation Planning: Anticipating the Legal Issues for Urban Planners. International Journal of Climate Change: Impacts and Responses, 2011, Vol. 2, N 3, p. 87-102. Disponible en Internet: http://www.academia.edu/420369/Climate_Adaptation_Planning_Anticipating_the_ Legal_Issues_for_Urban_Planners

EL MOSTRADOR. Aleuy: "Hay que hacer una discusión definitiva para no seguir construyendo bajo la cota de 20 metros". Santiago, Chile, 21 de Septiembre de 2015. (En sección: País, Diario El Mostrador). Disponible en Internet: https://www.elmostrador.cl/noticias/pais/2015/09/21/aleuyhay-que-hacer-una-discusion-definitiva-para-no-seguir-construyendo-bajo-la-cota-de-20-metros/

EIRD-ONU. Vivir con el riesgo. Informe mundial sobre iniciativas para la reducción de desastres: Informe Mundial sobre iniciativas para la reducción de desastres. Vol. 2. Ginebra, Suiza: Naciones Unidas EIRD, 2004. Disponible en Internet: https://www.preventionweb.net/globalplatform/2007/ first-session/docs/Background_docs/LwR-spa-volumen-2.pdf

EIRD-ONU. Terminología sobre Reducción del Riesgo de Desastres. Ginebra, Suiza: UNISDR, 2009. Disponible en Internet: https://unisdr.org/files/7817_UNISDRTerminologySpanish.pdf

FRANCHI-ARZOLA, I. Chile resiste pero puede y debe dejar de hacerlo. Santiago, Chile, 29 de Marzo de 2015. (En sección: Medio Ambiente, Diario El Quinto Poder). Disponible en Internet: http:// www.elquintopoder.cl/medio-ambiente/chile-resiste-pero-puede-y-debe-dejar-de-hacerlo/

HÁBITAT III. Documento Temático 15: Resiliencia urbana. In: Conferencia de las Naciones Unidas sobre la Vivienda y el Desarrollo Urbano Sostenible. Nueva York, 29 mayo de 2015. Disponible en Internet: http://habitat3.org/wp-content/uploads/Issue-Paper-15-Urban-Resilience.pdf

HERNÁNDEZ, R.; FERNÁNDEZ, C. y BAPTISTA, M. Metodología de la Investigación. 5ta. ed. México D.F.: McGraw-Hill, 2010.

HOLLING, C.S. Adaptative Environmental Assessment and Management. Chichester, Inglaterra: John Wiley \& Sons, 1978. 
INSTITUTO NACIONAL DE ESTADÍSTICAS (INE). Censo de Población y Vivienda 2017. Resultados Censo 2017. Santiago de Chile: INE: 2017.

JAQUE, E.; LARA, A. y MERINO GONZALEZ, C. Fortaleciendo el uso de los instrumentos de planificación urbana, para la gestión de riesgos. Ciudad de Coronel, Región del Biobío. Revista INVI, 2017, Vol. 32, No 90. p. 107-124. Disponible en Internet: https://dx.doi.org/10.4067/S071883582017000200107.

LAGOS, M.; CISTERNAS, M. y MARDONES, M. Construcción de Viviendas Sociales en Áreas de Riesgo de Tsunami. Revista de la Construcción, 2008, Vol. 7, № 2. p. 4-16. Disponible en Internet: http://www.redalyc.org/articulo.oa?id=127612584001

LA RED. Red de Estudios Sociales en Prevención de Desastres en America Latina. DesInventar Project: Chile - Inventario histórico de desastres. Disponible en Internet: http://online.desinventar.org/ desinventar/\#CHL-1257983285-chile_inventario_historico_de_desastres/

LATIN LAB, GSAPP COLUMBIA UNIVERSITY y SANTIAGO RESEARCH CELL. Learning from 27F: A Comparative Assessment Of Urban Reconstruction Processes After The 2010 Earthquake In Chile. Santiago, Chile: Santiago Research Cell, 2015. Disponible en Internet: https://researchgate.net/ publication/310166747_LEARNING_FROM_27F_A_Comparative_Assessment_Of_Urban_Reconstruction_Processes_After_The_2010_Eathquake_In_Chile

MINISTERIO DE VIVIENDA Y URBANISMO (MINVU). Política Nacional de Desarrollo Urbano. Ciudades Sustentables y Calidad de Vida. Santiago de Chile: PNUD, 2014. Disponible en Internet: http:// cndu.gob.cl/wp-content/uploads/2014/10/L4-Politica-Nacional-Urbana.pdf.

MINISTERIO DE VIVIENDA Y URBANISMO (MINVU). Resumen nacional: Estado de los planes reguladores. Santiago de Chile: MINVU, 2016. Disponible en Internet: http://observatorios.minvu.cl/ esplanurba/main.php? module=stat\&page=prc

MITCHELL, B. La gestión de los recursos y del medio ambiente. Ontario, Estados Unidos: Ediciones Mundi-Prensa, 1999.

MORIS, R. Notas respecto a los aprendizajes del proceso de reconstrucción en Chile después del 27 de febrero de 2010. Santiago, Chile: Centro Nacional de Investigación para la Gestión Integrada de Desastres Naturales (CIGIDEN), 2014. Disponible en Internet: http://academia.edu/11644418/ Notas_respecto_a_los_aprendizajes_del_proceso_de_reconstrucción_en_Chile_después_del_27_ de_febrero_de_2010

MORIS, R. Planificación y gestión integrada del riesgo. In: Seminario Chile Resiliente: Planificación y Gestión de Riesgos de Desastres Naturales. Santiago, Chile, 4 septiembre de 2015.

MORIS, R.; BERGAMINI, K.; TAMBURINI, L. y WALKER, R. Metodología de caracterización multiamenazas para las localidades de Chañaral, El Salado y Diego de Almagro, Región de Atacama. En: ENCINAS, F.; WECHSLER, A.; BUSTAMANTE, W y DÍAZ, F (editores). Intersecciones 2016, II Congre- 
so Interdisciplinario de Investigación en Arquitectura, Diseño, Ciudad y Territorio. Santiago, Chile: Ediciones ARQ, 2018.

NACIONES UNIDAS. Diagnóstico de la situación de la reducción del riesgo de desastres en Chile. Santiago, Chile: Naciones Unidas, 2010. Disponible en Internet: https://unisdr.org/we/inform/publications/18281

NARVÁEZ, L.; LAVELL, A. y PÉREZ, G. La Gestión del Riesgo de Desastres: Un enfoque basado en procesos. 1ra. ed. Lima, Perú: Comunidad Andina, 2009.

PLATT, S. y SO, E. Speed or deliberation: a comparison of post-disaster recovery in Japan, Turkey, and Chile. Disasters, 2017, Vol. 41, № 4. p. 696-727. Disponible en Internet: https://doi.org/10.1111/ disa.12219.

RANDOLPH, J. Environmental Land Use Planning and Management. 1era. ed. Virginia: Island Press, 2004.

SANTA MARÍA, M. Instrumentos de Planificación Territorial: Derechos y conflictos. Santiago: Instituto de Estudios Urbanos y Territoriales, 2015.

TAPIA, R. Vivienda y Emergencia ante desastres producidos por Sismos. Sismo de 1997 en la comuna de Punitaqui, Chile. Revista INVI, 2003, Vol. 18, N 47. p. 89-103. Disponible en Internet: http://revistainvi.uchile.cl/index.php/INVI/article/view/394/814.

TAPIA, R. Terremoto 2010, Chile: Evaluación de la aplicación de normativa urbana/rural en políticas públicas. Algunos resultados. En: ARTEAGA, C. y TAPIA, R. Vulnerabilidades y desastres socionaturales: experiencias recientes en Chile. Santiago, Chile: Editorial Universitaria, 2014. p. 41-59. Disponible en Internet: http://repositorio.uchile.cl/handle/2250/130243

TAPIA, R. Acción del Estado y acción comunitaria en la gestión de la vivienda post erupción del volcán Chaitén, Chile: dos estrategias divergentes. Magallania, 2016, Vol. 43, № 3. p. 141-158. Disponible en Internet: https://dx.doi.org/10.4067/S0718-22442015000300011

THOMALLA, F.; BOYLAND, M.; JOHNSON, K.; ENSOR, J.; TUHKANEN, H.; GERGER SWARTLING, Å.; HAN, G.; FORRESTER, J. y WAHL, D. Transforming Development and Disaster Risk. Sustainability, 2018, Vol. 10, N 5, p. 1458. Disponible en Internet: http://dx.doi.org/10.3390/su10051458

UNESCO. Análisis de riesgos de desastres en Chile: VII Plan de Acción DIPECHO en Sudamérica 2011-2012. Santiago: UNESCO, 2012. Disponible en Internet: http://unesdoc.unesco.org/images/0023/002329/232991s.pdf

UNICEF, COORDINACIÓN EDUCATIVA Y CULTURAL CENTROAMERICANA (CECC/SICA) y COMUNIDAD EUROPEA. La gestión integral del riesgo: Un derecho de la comunidad educativa. Guía para la elaboración de planes de gestión del riesgo en instituciones educativas. Ciudad de Panamá: UNICEF/TACRO, 2010. Disponible en Internet: https://unicef.org/panama/spanish/herramienta2.pdf 
VALENCIA, M. y REED, P. Con último terremoto, 12 de 15 regiones tienen obras de reconstrucción por catástrofes. Santiago, Chile, 22 de Septiembre de 2015. p. C. (En sección: Nacional, Diario El Mercurio). Disponible en Internet: http://diario.elmercurio.com/detalle/index.asp?id=\{a3374ff9-9d1d-4ebc-a35a-9c3d5fd76462\}

VALENCIA, M. Un cuarto de las comunas no cuenta con plan regulador, y solo el $34 \%$ del total está vigente. Santiago, Chile, 27 de Septiembre de 2015. p. C12. (En sección: Nacional, Diario El Mercurio). Disponible en Internet: http://diario.elmercurio.com/detalle/index.asp?id=\{078a279da5f7-4117-8a9f-a3f4498f5ff6\}

VILLAGRA, P.; HERRMANN, G.; QUINTANA, C. y SEPULVEDA, R.D. El pensamiento resiliente y la planificación urbana en un entorno costero bajo riesgo de tsunami: el caso de Mehuín, Chile. Revista de Geografía Norte Grande, 2016, № 64, p. 55-62. Disponible en Internet: https://dx.doi. org/10.4067/S0718-34022016000200005 